\title{
Selective Impairment of Hippocampal Gamma Oscillations in Connexin-36 Knock-Out Mouse In Vivo
}

\author{
Derek L. Buhl, ${ }^{1}$ Kenneth D. Harris, ${ }^{1}$ Sheriar G. Hormuzdi, ${ }^{2}$ Hanna Monyer, ${ }^{2}$ and György Buzsáki ${ }^{1}$ \\ ${ }^{1}$ Center for Molecular and Behavioral Neuroscience, Rutgers University, The State University of New Jersey, Newark, New Jersey 07102, and ${ }^{2}$ Department of \\ Clinical Neurobiology, University Hospital of Neurology, 69120 Heidelberg, Germany
}

The physiological roles of neuronal gap junctions in the intact brain are not known. The recent generation of the connexin-36 knock-out ( Cx36 K0) mouse has offered a unique opportunity to examine this problem. Recent in vitro recordings in Cx36 K0 mice suggested that Cx36 gap junction contributes to various oscillatory patterns in the theta $(\sim 5-10 \mathrm{~Hz})$ and gamma $(\sim 30-80 \mathrm{~Hz})$ frequency ranges and affects certain aspects of high-frequency $(>100 \mathrm{~Hz})$ patterns. However, the relevance of these pharmacologically induced patterns to the intact brain is not known. We recorded field potentials and unit activity in the CA1 stratum pyramidale of the hippocampus in the behaving wild-type (WT) and Cx36 KO mice. Fast-field "ripple" oscillations $(140-200 \mathrm{~Hz})$ were present in both WT and K0 mice and did not differ significantly in power, intraepisode frequency, or probability of occurrence. Thus, fast-field oscillations either may not require electrical synapses or may be mediated by a hitherto unknown class of gap junctions. Theta oscillations, recorded during either wheel running or rapid eye movement sleep, were not different either. However, the power in the gamma frequency band and the magnitude of theta-phase modulation of gamma power were significantly decreased in KO mice compared with WT controls during wheel running. This suggests that $\mathrm{Cx} 36$ interneuronal gap junctions selectively contribute to gamma oscillations.

Key words: theta; gamma; ripple; oscillation; EEG; unit; gap junction; connexin-36

\section{Introduction}

Cooperative activity of central neurons is often expressed in the form of network oscillations (Gray, 1994; Buzsáki and Chrobak, 1995). During exploratory, appetitive behaviors and rapid eye movement (REM) sleep, rhythmic network oscillations, theta $(\sim 5-10 \mathrm{~Hz})$ and gamma $(\sim 30-80 \mathrm{~Hz})$ waves, are present in the hippocampal formation (Vanderwolf, 1969; Buzsáki, 2002). In the absence of theta activity, irregular sharp waves in the CA1 stratum radiatum and associated fast-field oscillations (or "ripples"; $\sim 140-200 \mathrm{~Hz}$ ) in the CA1 pyramidal cell layer (O'Keefe and Nadel, 1978; Buzsáki et al., 1992) are present during waking immobility, consummatory behaviors, and slow-wave sleep (SWS).

The neuronal mechanisms that underlie fast oscillations in the hippocampus $(140-200 \mathrm{~Hz})$ and neocortex $(300-600 \mathrm{~Hz})$ are poorly understood (Buzsáki et al., 1992; Ylinen et al., 1995; Kandel and Buzsáki, 1997; Draguhn et al., 1998; Bragin et al., 1999; Jones and Barth, 1999, 2002; Curio, 2000; Jones et al., 2000; Grenier et al., 2001; Traub et al., 2001; Maier et al., 2002). Neuronal populations underlying the ripple are believed to be synchronized by fast synaptic mechanisms (Buzsáki et al., 1983; Ylinen et al., 1995; Jones et al., 2000), interneuronal gap junctions (Ylinen et al., 1995), and/or gap junctions across pyramidal cells (Draguhn et al., 1998; Traub et al., 1999; Traub and Bibbig, 2000; Schmitz et al., 2001; Jones and Barth, 2002; Maier et al., 2002).

Received 0ct. 3, 2002; revised 0ct. 31, 2002; accepted Nov. 1, 2002.

This research was supported by National Institutes of Health Grants NS34994 and MH54671, Deutsche Forschungsgemeinschaft Sonderforschungsbereich 488, The Schilling Foundation, and Novartis.

Correspondence should be addressed to György Buzsáki, Center for Molecular and Behavioral Neuroscience, Rutgers University, The State University of New Jersey, 197 University Avenue, Newark, NJ 07102. E-mail: buzsáki@axon.rutgers.edu.

Copyright $\odot 2003$ Society for Neuroscience $\quad 0270-6474 / 03 / 231013-06 \$ 15.00 / 0$
Inhibitory interneurons have been hypothesized to play a critical role in both theta and gamma oscillations (Buzsáki et al., 1983; Leung and Yim, 1986; Fox, 1989; Traub et al., 1992; Whittington et al., 1995; Wang and Buzsáki, 1996; Penttonen et al., 1998; Buzsáki, 2002). Because cortical interneurons are known to be interconnected by gap junctions (Katsumaru et al., 1988; Gibson et al., 1999; Beierlein et al., 2000; Fukuda and Kosaka, 2000; Tamas et al., 2000; Galarreta and Hestrin, 2001; Amitai et al., 2002), electrical communication may assist the emergence of these slower rhythms also (Traub et al., 2000).

The recent generation of the connexin-36 knock-out (Cx36 $\mathrm{KO})$ mouse offers a unique opportunity for studying the functional roles of interneuronal gap junction communication. In vitro and modeling studies have observed either no difference (Hormuzdi et al., 2001; Traub et al., 2002) or a significant decrease in both ripple incidence and intraripple frequency (Maier et al., 2002) in KO animals relative to wild-type (WT) mice. The lack of the Cx36 gap junction also disrupted hippocampal gamma-like frequency oscillations in vitro (Hormuzdi et al., 2001) and reduced the synchrony of rhythmic inhibitory potentials in the theta and gamma frequency bands in the neocortex (Deans et al., 2001). However, in vitro studies are limited because oscillations are induced by either stimulation or pharmacological means, and the slice preparation lacks proper network connectivity. Therefore, we examined the effect of the deletion of Cx36 protein on hippocampal network activity in vivo. We found a selective impairment of gamma oscillations, with no effect on the slower theta or the faster ripple patterns.

\section{Materials and Methods}

Generation of connexin-36 KO mice. Cx36 KO mice, lacking the second exon of the $C \times 36$ gene, were generated as described previously by Hormuzdi et al. (2001). As demonstrated by in situ hybridization, there is a 
complete absence of connexin 36-containing gap junctions in the brain, including the CA1 region, the focus of this study.

Animals and surgery. Male $\mathrm{KO}(\mathrm{Cx} 36 \mathrm{KO} ; n=9)$ and WT $(n=9)$ mice (four Cx36 littermates and five male progeny of C57B6/J and 129S6/ SvEvTac hybrids) were anesthetized with a mixture $(4 \mathrm{mg} / \mathrm{kg})$ of ketamine $(25 \mathrm{mg} / \mathrm{ml})$, xylazine $(1.3 \mathrm{mg} / \mathrm{ml})$, and acepromazine $(0.25 \mathrm{mg} /$ $\mathrm{ml}$ ) via an intramuscular injection. All WT mice were compared to ensure that no physiological differences were present (Buzsáki et al., 2003). Holes above the hippocampus $(\sim 1 \mathrm{~mm}$ in diameter) were drilled bilaterally $1.7 \mathrm{~mm}$ posterior to bregma and $\pm 1.0 \mathrm{~mm}$ lateral to the midline. To record field potentials and unit activity, two tetrodes or $60 \mu \mathrm{m}$ wires were fixed on a movable drive. Tetrodes (Recce and O'Keefe, 1989) were constructed from four $12 \mu \mathrm{m}$ polyimide-coated nichrome wires (H. P. Reid, Palm Coast, FL) bound together by twisting and then melting their insulation (Gray et al., 1995). Each complete turn of the microdrive moved the recording electrode $\sim 0.3 \mathrm{~mm}$ axially. During surgery, the electrodes were placed bilaterally $\sim 0.5 \mathrm{~mm}$ into the neocortex, directly above the CA1 region of the hippocampus, according to Franklin and Paxinos (1997). The holes were then covered with a mixture of paraffin oil and wax. Two stainless steel screws were driven into the skull above the frontal cortex and served as ground and reference electrodes and anchors. Two screws were also implanted posterior to lambda to serve as anchors. After the electrodes and anchors were in position, the microdrive was fixed to the skull with dental acrylic. Each mouse was then placed one to a cage, in which food and a dish of water were placed on the floor of the cage for easy access. Recordings began after a recovery period of at least $24 \mathrm{hr}$. The electrodes were slowly positioned in the target layers, and recordings continued for $\sim 2$ weeks. All procedures conformed to the National Institutes of Health Guide for the Care and Use of Laboratory Animals and had been approved by the Institutional Animal Care and Use Committee of Rutgers University.

Data acquisition. Electrical activity was recorded during SWS and REM sleep in the animal's home cage and during the wake cycle while the animal was running in a wheel. The apparatus consisted of a running wheel $(29.5 \mathrm{~cm}$ in diameter $)$ and adjacent box $(30 \times 40 \times 35 \mathrm{~cm})$ (Czurkó et al., 1999). The mice were allowed to freely explore the apparatus and run in the wheel. Instrumentation amplifiers, built in the female connector (16 channels), were used to reduce cable movement artifacts. Initially, one recording electrode was lowered slowly into the CA1 region of the hippocampus while the other remained in the neocortex. The position of the electrode in the CA1 pyramidal layer was determined by the presence of fast oscillations (ripples) in association with synchronous discharge of pyramidal cells and interneurons (Buzsáki et al., 2003). Field potential and unit activity were recorded after being amplified $(2000-5000 \times)$ and bandpass filtered (1 Hz to $3 \mathrm{kHz}$ ) (model 12-24 channel; Grass Instruments, Quincy, MA), digitized with 12-bit resolution continuously at $10-20 \mathrm{kHz}$ (ISC-16 analog-to-digital converter; R. C. Electronics, Santa Barbara, CA), and recorded on a 486 personal computer. The data were analyzed offline. When bilateral recordings were made, recordings from each hemisphere were treated as independent data.

Data processing and analysis. All analyses and statistics were calculated using custom scripts written for Matlab 6.1 for LINUX (MathWorks, Natick, MA).

Spike sorting. Putative cells were isolated using methods described previously by Csicsvari et al. $(1998,1999)$ and Harris et al. (2000). In short, the wide-band recorded signals were digitally high-pass filtered $(0.8-5$ $\mathrm{kHz}$ ). The power (root mean square) of the filtered signal was computed in a sliding window $(0.2 \mathrm{msec})$ for spike detection. Spikes with a power threshold (mean $+5 \mathrm{SD})$ were extracted. CA1 pyramidal cells and interneurons were identified and isolated from the extracted spikes on the basis of amplitudes and wave shapes by first using an autoclustering method (Harris et al., 2000). After autoclustering, units were further isolated using a manual cluster cutting method (Csicsvari et al., 1999). Units showing a refractory period $\geq 2 \mathrm{msec}$ were considered single units. Units recorded from the $60 \mu \mathrm{m}$ wires were treated as multiunit activity.

Detection of ripple, theta, and gamma events. The beginning, middle, and end of CA1 ripple events were detected by applying an amplitude threshold (mean $+7 \mathrm{SD})$ to the previously bandpass-filtered (150-250
$\mathrm{Hz}$ ) electroencephalogram (EEG). Theta and gamma epochs, amplitudes, and phases were detected by applying Hilbert transform to the previously bandpass-filtered (4-12 and $30-80 \mathrm{~Hz}$, respectively) EEG (Le Van Quyen et al., 2001). The mean gamma amplitude was then calculated for every $10^{\circ}$ of the theta cycle.

Histology. After the collection of the data, mice were deeply anesthetized with a high dose of Nembutal $(100 \mathrm{mg} / \mathrm{kg})$. With the electrodes left in situ, animals were perfused transcardially with saline $(\sim 15 \mathrm{ml})$, followed by $50 \mathrm{ml}$ of phosphate-buffered $(0.1 \mathrm{M})$ fixative ( $4 \%$ paraformaldehyde, $0.15 \%$ picric acid, and $0.05 \%$ glutaraldehyde). Brains were extracted, blocked within range of the hippocampus, and placed in fixative for $24-48 \mathrm{hr}$. The brains were then cut into $80-\mu \mathrm{m}$-thick sections using a vibratome. For verification of electrode placement, sections were mounted onto gelatin-coated slides, stained with the Nissl method, dehydrated, and covered with Depex for light microscopy.

\section{Results}

\section{Comparison of fast-field ripple oscillations during slow-wave sleep}

As in the rat, ripple events could be resolved by eye in wide-band ( $1 \mathrm{~Hz}$ to $3 \mathrm{kHz}$ ) recordings (Fig. $1 A$ ). Only ripple events occurring during slow-wave sleep were used in these analyses. The mean probability of ripple episode ( $>7 \mathrm{SD}$ episodes) occurrence was $0.68 \pm 0.07 / \mathrm{sec}$ for the $\mathrm{KO}$ and $0.69 \pm 0.03 / \mathrm{sec}$ for the WT group. The magnitude and frequency of ripples in Cx36 KO and WT mice were compared quantitatively by two methods. First, spectral power was calculated for the entire slow-wave sleep session (5-20 $\mathrm{min}$ ), and the cumulative power in the $100-200 \mathrm{~Hz}$ band was used to quantify ripples. Neither the power nor the peak frequency of ripple band was significantly different for the two groups (Fig. $1 B)(p>0.05$; Wilcoxon rank sum test). In the second approach, the ripple episodes were first detected by the threshold criteria, and a multitaper method was used to calculate ripple power (see Materials and Methods). Again, both the mean power and frequency $(\mathrm{WT}, \sim 149 \mathrm{~Hz} ; \mathrm{KO}, \sim 150 \mathrm{~Hz}$ ) were similar in the two groups (Fig. $1 B$, inset) $(p>0.05$; Wilcoxon rank sum test).

\section{Theta and gamma oscillations in WT and KO mice}

Theta and gamma epochs recorded during wheel running and REM sleep were analyzed separately. Theta and gamma epochs during REM sleep episodes were obtained from the same sleep session from which ripples were recorded during slow-wave sleep. To attain accurate measurements, the data were limited to steady, uninterrupted wheel running and REM periods (i.e., $>10$ sec periods in which the theta epochs were steady and static). Theta power (6-9 Hz cumulative power) in the $\mathrm{KO}$ mice was not significantly different from that in the WT mice either during REM sleep (Fig. 2A) or awake wheel running sessions (Fig. 2B) $(p>0.1)$. In contrast, the power at frequencies $>20 \mathrm{~Hz}$ were different in the two groups. Gamma power $(30-80 \mathrm{~Hz}$ cumulative power) was significantly lower in KO mice than in WT animals during wheel running $(p<0.0001)$, although not during REM sleep (Fig. 2). The group data, shown in Figure 2, are from all mice (KO, $n=7$; WT, $n=11$ ). When the data were limited to mice in which slow-wave sleep, REM sleep, and wheel running sessions were recorded in a single experiment $(\mathrm{KO}, n=5$; WT, $n=6)$, the group differences remained the same $(<0.001)$.

The next analysis addressed the relationship between theta phase and the magnitude of gamma oscillation (Bragin et al., 1995; Buzsáki et al., 2003). For each recording, instantaneous gamma power was measured during every $10^{\circ}$ bin of the theta cycle. These calculations showed that the power of gamma activity fluctuated periodically and reached maximum values at 


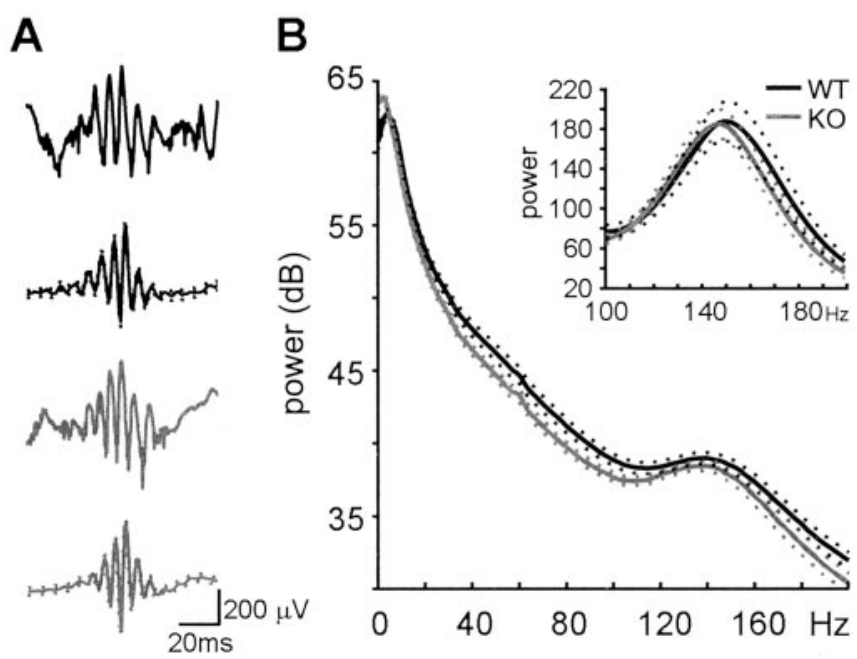

Figure 1. Ripples are not affected by deletion of CX36 gap junction. $A$, Examples of ripple episodes (1.0 Hz to $3 \mathrm{kHz}$ ) in representative WT and Cx36 K0 animals (top traces). Averaged ripples for the two mice. Mean \pm SEM. B, Comparison of ripple power between WT and Cx36 KO animals. Averaged power spectra for all mice in the respective groups (mean $\pm \mathrm{SEM}$ ) during slow-wave sleep (5-10 min sessions). Note similarly increased power between 100 and $200 \mathrm{~Hz}$, corresponding to ripple power in both groups. Inset, Power of isolated ripple episodes (7 SD above background mean; see Materials and Methods). Note similar peak frequency and power in both groups.

$14.4 \pm 1.7^{\circ}(\mathrm{WT})$ and $32.0 \pm 5.1^{\circ}(\mathrm{KO})$ after the theta peak recorded in the CA1 pyramidal layer during REM sleep (Fig. $3 A$ ), and $35.5 \pm 6.4^{\circ}(\mathrm{WT})$ and $35.7 \pm 4.3^{\circ}(\mathrm{KO})$ were obtained during wheel running (Fig. 3B). These findings indicated that the mechanism responsible for the theta-phase locking of gamma power operated identically in the two groups. The magnitude of instantaneous power across the theta cycle was lower in the KO group during wheel running, confirming the gamma power measurements in the spectral data (Fig. 2). This difference was larger on the peak portion of the theta cycle than on the trough. To quantify this observation, we calculated the "theta modulation depth" of gamma power by normalizing the curves to the trough of theta in each animal. The magnitude of modulation depth was not significantly different in Cx36 mice compared with WT controls during REM sleep $(p>0.1)$ but was significantly less in Cx36 mice during wheel running $(p<0.02)$.

The mean firing rates of pyramidal cells were similar during both wheel running (WT, $2.76 \pm 0.45 \mathrm{~Hz}, n=17$ cells; KO, $2.40 \pm 0.30 \mathrm{~Hz}, n=20)$ and REM sleep (WT, $1.91 \pm 0.38 \mathrm{~Hz}, n=$ 16 ; $\mathrm{KO}, 1.28 \pm 0.19 \mathrm{~Hz}, n=26)$. These averages may overestimate the mean firing rate of all pyramidal neurons because most pyramidal cells discharge at a very low rate $(0.1 \mathrm{~Hz})$ and therefore are not detected by the clustering method (Harris et al., 2000). The firing rates of interneurons were $17.03 \pm 3.20 \mathrm{~Hz}$ (WT, $n=$ $13)$ and $10.43 \pm 1.96 \mathrm{~Hz}(\mathrm{KO}, n=24)$ during wheel running and $13.10 \pm 3.39 \mathrm{~Hz}(\mathrm{WT}, n=8)$ and $21.06 \pm 3.43 \mathrm{~Hz}(\mathrm{KO}, n=13)$ during REM sleep. These differences were not statistically significant. The phase relationship between theta oscillation and unit discharge is summarized in Figure 4. Neurons recorded in either REM or wheel running sessions were combined to increase the data base. Pyramidal neurons in the WT group had two peaks, one $\sim 30^{\circ}$ after the trough of theta waves recorded in the pyramidal layer and another maximum at the peak of the theta cycle (Fig. $4 A$ ). The double peak was not necessarily a result of combining neurons with distinct phase preferences, because double peaks were also observed in theta-phase histograms of individual units

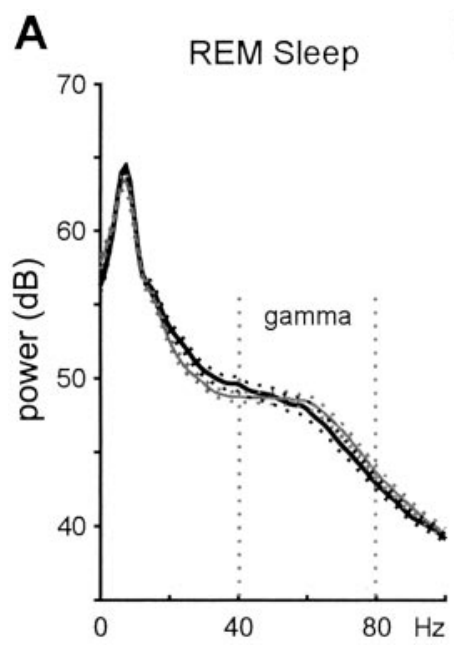

B Wheel Running

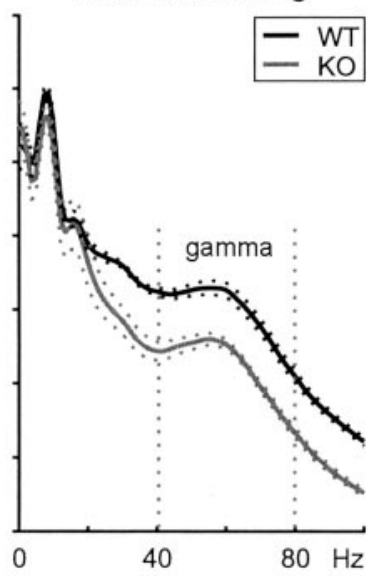

Figure 2. Gamma power is impaired in CX36 K0 mice. Group mean \pm SEM power spectra for $\mathrm{KO}$ and WT mice during REM sleep $(A)$ and wheel running $(B)$ sessions. Note large difference in power for frequencies $>20 \mathrm{~Hz}$.

(Buzsáki et al., 2003). In KO animals, the maximum discharge probability occurred slightly after the trough of theta $\left(30-60^{\circ}\right)$, and increased discharge associated with the peak of theta was not prominent. These differences were not significantly different across the groups. Note, however, that the largest difference between the two groups occurred at the phase of theta in which the largest difference in gamma power was detected (compare with Fig. 3). Individual interneurons showed a stronger theta-phase locking than pyramidal cells, but the theta phase-unit relationship showed considerable variability across interneurons. As a group, interneurons discharged maximally $30-120^{\circ}$ before the theta trough in WT mice (Fig. $4 B$ ), i.e., on the descending portion of the theta waves. In the $\mathrm{KO}$ group, the maximum discharge probability occurred after the theta trough. The relative phase shift of the firing peaks may be because of technical factors. The peak of theta was determined with the Hilbert transform (see Materials and Methods), and the differential theta-phase locking of gamma power (see above) may have affected the determination of zero phase because of the nonsinusoidal nature of theta waves.

\section{Discussion}

The three field patterns in the hippocampus addressed in the present study (theta, 5-9 Hz; gamma, $~ 30-80 \mathrm{~Hz}$; and ripples, $\sim 140-200 \mathrm{~Hz}$ ) have been studied extensively in the rat. These field patterns are also present in the mouse and are comparable with those studied in the rat (Buzsáki et al., 2003). The present results suggest that the power of gamma oscillations is selectively decreased in mice lacking Cx36 gap junctions, without affecting gamma frequency or other network patterns.

\section{Cx36 involvement in gamma oscillations}

Interneurons have been suggested to play a pivotal role in theta and gamma oscillations (Buzsáki et al., 1983; Buzsáki and Chrobak, 1995; Freund and Buzsáki, 1996; Traub et al., 1999; McBain and Fisahn, 2001). Because interneurons are connected to each other by both chemical synapses and gap junctions (Katsumaru et al., 1988; Tamas et al., 2000; Amitai et al., 2002), an important issue is whether and how electrotonic communication in networks of interneurons contributes to the various brain rhythms. Although gap junctions have been hypothesized to "as- 
sist" chemical synapses with faster oscillations (Buzsáki, 2001; Galarreta and Hestrin, 2001), slower rhythms $(<100 \mathrm{~Hz})$ have typically been thought to be mediated predominantly by chemical synapses. The present findings and recent in vitro experiments suggest, however, that interneuronal gap junctions may play a role in the generation of network oscillations in the gamma frequency range.

Recording from the stratum radiatum of the CA3 region, Hormuzdi et al. (2001) reported that $\mathrm{Cx} 36 \mathrm{KO}$ mice consistently yielded significantly lower-amplitude gamma oscillations when gamma was pharmacologically induced by application of kainate or carbachol. The frequency of induced gamma oscillation was not different between the two groups. In addition, they also showed a significant difference in the duration of IPSPs in $\mathrm{KO}$ interneurons recorded from the CA3 stratum pyramidale. Deans et al. (2001), recording from pairs of neocortical low-threshold spiking (LTS) cells rather than from the extracellular medium, found a significant impairment in the synchronous features of LTS-based inhibition in the local area network in Cx36 KO mice. Both studies found electrical coupling in nearby interneurons to be nearly absent in $\mathrm{Cx} 36 \mathrm{KO}$ animals. These latter observations suggest that predominantly one type of gap junction, Cx36, is present among these interneurons. Together, those in vitro and the present in vivo observations indicate a similar impairment of gamma oscillations in the absence of interneuronal gap junctions, i.e., a significant decrease of local synchrony as reflected by the power of the field but without alteration of the dominant frequency.

It was also suggested that the lack of the $\mathrm{Cx} 36$ gap junctions affects oscillations in the lower-frequency range in the neocortex (Deans et al., 2001). In our experiments, neither the power nor the frequency of hippocampal theta oscillations was altered.

The difference of gamma power between the KO and control groups was larger during wheel running than during sleep. It may be argued that this difference may be artifactual, resulting from some impairment of ambulation in the $\mathrm{Cx} 36 \mathrm{KO}$ mice. Although this argument cannot be completely dismissed with the available data, to date, behavioral tests have failed to reveal any differences in motor activity between $\mathrm{Cx} 36 \mathrm{KO}$ and control animals (Long et al., 2002). Importantly, differences in ambulatory behavior should have been reflected by differences in theta power (Czurkó et al., 1999), which was not found to be the case here. We hypothesize that the difference in gamma power during wheel running versus REM sleep could be explained by the more effective modulation of $\mathrm{Cx} 36$ gap junctions by subcortical neurotransmitters in the awake animal.

\section{Lack of Cx36 involvement in fast-field ripple oscillations}

The observation in the intact rat that halothane, a nonspecific gap junction blocker, abolished hippocampal ripples prompted the suggestion that electrical coupling among neurons may be critical in the generation of superfast network oscillations (Ylinen et al., 1995). Our present findings indicate, however, that interneuronal Cx36 gap junctions are most likely not involved. No aspect of hippocampal ripples was quantitatively different between $\mathrm{KO}$ and WT animals. Furthermore, neocortical ripples were also present in $\mathrm{KO}$ mice (our unpublished observations). In light of the impairment of gamma oscillations, this finding is surprising, because ripples in the CA1 region are a result of a cooperative coupling of gamma oscillators in the CA3 region (Csicsvari et al., 2000). A possible explanation of this discrepancy is that transient gamma oscillation bursts, present in the absence of theta activity at times at which release of subcortical neurotransmitters is reduced, do not require wide-range coupling of interneurons via gap junctions. This conjecture is supported by the less pronounced deficit of gamma power during REM sleep in Cx36deficient mice.

At least two factors contribute to the field ripples. Synchronous discharge of pyramidal neurons generate repetitive "mini population spikes" (Buzsáki, 1986) that are responsible for the spike-like appearance of the troughs of ripples in the pyramidal cell layer. The positive "wave" component has been suggested to reflect synchronously occurring IPSPs in pyramidal cells (Ylinen et al., 1995; Jones et al., 2000; Grenier et al., 2001). Ripple-like patterns, consisting of transient oscillation of mini population spikes only, were described recently in vitro (Draguhn et al., 1998). The in vitro oscillations persist after blockade of inhibition (Jones and Barth, 2002) or even after complete blockade of synaptic transmission. On the basis of these in vitro observations and computer simulations, it was proposed that ripple oscillations were mediated by electrical coupling that occurred between the axons of pyramidal cells (Draguhn et al., 1998, 2000; Traub et al., 1999; Traub and Bibbig, 2000). However, the overall appearance, intraepisode frequency, and amplitude of ripple-like events in Cx36-deficient mice were found to be identical to those in WT mice (Hormuzdi et al., 2001). A more recent study, conversely, reported that the incidence of ripple-like events recorded in the CA1 region and their intraepisode frequencies were significantly reduced in Cx36 KO mice compared with WT animals (Maier et al., 2002).

Although the ripple-like events in the slice may capture some important aspects of the analogous events in the intact brain, they are not identical with it. Ripple-like events in vitro are present right after birth (Palva et al., 2000), whereas ripples in vivo first emerge during the late part of the second week of life in rats (Leinekugel et al., 2002). The latter observation further supports 


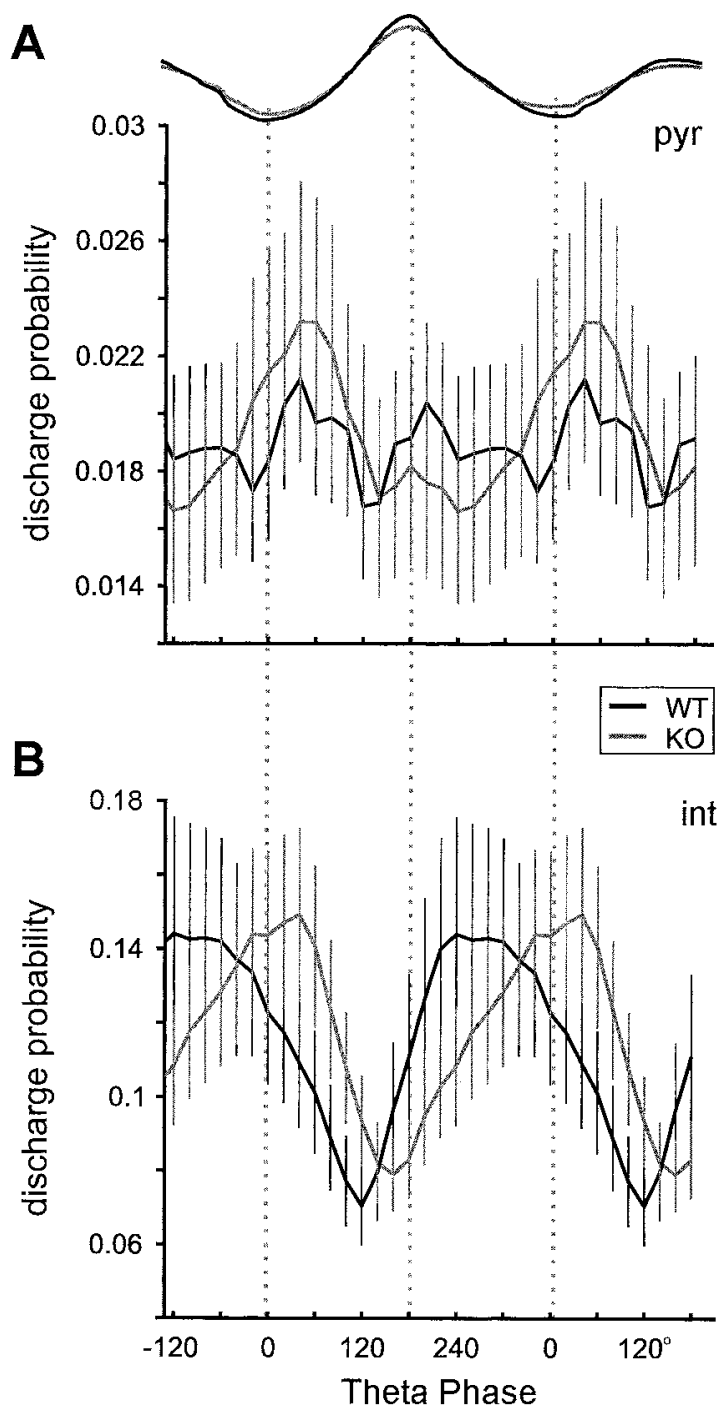

Figure 4. Theta phase and unit activity. $A$, Pyramidal cells ( $p y r$ ) (WT, $n=31$ neurons; KO, $n=50) . B$, Interneurons (int) (WT, $n=21 ; K 0, n=34$ ). A, Top traces, Grand mean theta waves (1 Hz to $3 \mathrm{kHz}$ ) from WT (thick line) and KO (thin line) mice, combined from REM and wheel running sessions. Graphs shows mean \pm SEM.

the idea that $\mathrm{Cx} 36$ gap junctions are not involved in ripple generation, because Cx36 messenger RNA declines during the first two postnatal weeks in both rat and mouse (Peinado et al., 1993; Söhl et al., 1998; Condorelli et al., 2000). If gap junctions are critical in the emergence of ripple oscillations, their developmental profile should match that of the physiological events underlying ripple generation. An additional difficulty is that electrical coupling between pairs of pyramidal cells has never been observed (Gibson et al., 1999; Beierlein et al., 2000; Venance et al., 2000; Deans et al., 2001; Soh et al., 2001). It is possible that other electrical junctions (Stebbings et al., 2002), different from the connexin family, exist in the mammalian brain also and that these junctions open only under special voltage or other circumstances. A complicating aspect of this idea is that ripple-like oscillations are blocked by the connexin-specific octanol, halothane, and carbenoxolene in vitro (Draguhn et al., 1998), whereas these agents do not affect nonconnexin-type electronic junctions (Stebbings et al., 2002). Additional research will determine whether hitherto unidentified electrical junctions are essential for ripple oscillations in the hippocampus and neocortex and whether their abolishment will impair superfast oscillations in the intact mammalian brain.

On the basis of specific neuronal expression, gene structure, and phylogenetic analysis, it has been proposed that $\mathrm{C} \times 35 / 36$ proteins represent a distinct subgroup of the connexin family. Genetic localization mapped the human $C \times 36$ gene to chromosomal band 15q14 (Belluardo et al., 1999). Because a form of juvenile myoclonic epilepsy has also been linked to this region (Elmslie et al., 1997; Sander et al., 1997), it was suggested that diminished gap junction communication among interneurons is linked to the disease. We have not found any physiological or behavioral alterations indicative of seizures. The relatively selective deficit in gamma oscillations may predict more subtle cognitive deficits, including impaired perception and memory.

\section{References}

Amitai Y, Gibson JR, Beierlein M, Patrick SL, Ho AM, Connors BW, Golomb D (2002) The spatial dimensions of electrically coupled networks of interneurons in the neocortex. J Neurosci 22:4142-4152.

Beierlein M, Gibson JR, Connors BW (2000) A network of electrically coupled interneurons drives synchronized inhibition in neocortex. Nat Neurosci 3:904-910.

Belluardo N, Trovato-Salinaro A, Mudo G, Hurd YL, Condorelli DF (1999) Structure, chromosomal localization, and brain expression of human Cx36 gene. J Neurosci Res 57:740-752.

Bragin A, Jandó G, Nádasdy Z, Hetke J, Wise K, Buzsáki G (1995) Gamma $(40-100 \mathrm{~Hz})$ oscillation in the hippocampus of the behaving rat. J Neurosci 15:47-60.

Bragin A, Engel Jr J, Wilson CL, Fried I, Buzsáki G (1999) High-frequency oscillations in human brain. Hippocampus 9:137-142.

Buzsáki G (1986) Hippocampal sharp waves: their origin and significance. Brain Res 398:242-252.

Buzsáki G (2001) Electrical wiring of the oscillating brain. Neuron 31:342-344.

Buzsáki G (2002) Theta oscillations in the hippocampus. Neuron 33:325-340.

Buzsáki G, Chrobak JJ (1995) Temporal structure in spatially organized neuronal ensembles: a role for interneuronal networks. Curr Opin Neurobiol 5:504-510.

Buzsáki G, Leung LW, Vanderwolf CH (1983) Cellular bases of hippocampal EEG in the behaving rat. Brain Res 287:139-171.

Buzsáki G, Horvath Z, Urioste R, Hetke J, Wise K (1992) High-frequency network oscillation in the hippocampus. Science 256:1025-1027.

Buzsáki G, Buhl D, Harris K, Csiscvari J, Czeh B, Morozov A (2003) Hippocampal network patterns of activity in the mouse. Neuroscience, in press.

Condorelli DF, Belluardo N, Trovato-Salinaro A, Mudo G (2000) Expression of Cx36 in mammalian neurons. Brain Res Brain Res Rev 32:72-85.

Csicsvari J, Hirase H, Czurkó A, Buzsáki G (1998) Reliability and state dependence of pyramidal cell-interneuron synapses in the hippocampus: an ensemble approach in the behaving rat. Neuron 21:179-189.

Csicsvari J, Hirase H, Czurkó A, Mamiya A, Buzsáki G (1999) Oscillatory coupling of hippocampal pyramidal cells and interneurons in the behaving rat. J Neurosci 19:274-287.

Csicsvari J, Hirase H, Mamiya A, Buzsáki G (2000) Ensemble patterns of hippocampal CA3-CA1 neurons during sharp wave-associated population events. Neuron 28:585-594.

Curio G (2000) Ain't no rhythm fast enough: EEG bands beyond beta. J Clin Neurophysiol 17:339-340.

Czurkó A, Hirase H, Csicsvari J, Buzsáki G (1999) Sustained activation of hippocampal pyramidal cells by "space clamping” in a running wheel. Eur J Neurosci 11:344-352.

Deans MR, Gibson JR, Sellitto C, Connors BW, Paul DL (2001) Synchronous activity of inhibitory networks in neocortex requires electrical synapses containing connexin36. Neuron 31:477-485.

Draguhn A, Traub RD, Schmitz D, Jefferys JG (1998) Electrical coupling underlies high-frequency oscillations in the hippocampus in vitro. Nature 394:189-192.

Draguhn A, Traub RD, Bibbig A, Schmitz D (2000) Ripple (approximately 
$200-\mathrm{Hz}$ ) oscillations in temporal structures. J Clin Neurophysiol 17:361-376.

Elmslie FV, Rees M, Williamson MP, Kerr M, Kjeldsen MJ, Pang KA, Sundqvist A, Friis ML, Chadwick D, Richens A, Covanis A, Santos M, Arzimanoglou A, Panayiotopoulos CP, Curtis D, Whitehouse WP, Gardiner RM (1997) Genetic mapping of a major susceptibility locus for juvenile myoclonic epilepsy on chromosome 15q. Hum Mol Genet 6:1329-1334.

Fox SE (1989) Membrane potential and impedance changes in hippocampal pyramidal cells during theta rhythm. Exp Brain Res 77:283-294.

Franklin BJK, Paxinos G (1997) The mouse brain in stereotaxic coordinates. San Diego: Academic.

Freund TF, Buzsáki G (1996) Interneurons of the hippocampus. Hippocampus 6:347-470.

Fukuda T, Kosaka T (2000) Gap junctions linking the dendritic network of GABAergic interneurons in the hippocampus. J Neurosci 20:1519-1528.

Galarreta M, Hestrin S (2001) Spike transmission and synchrony detection in networks of GABAergic interneurons. Science 292:2295-2299.

Gibson JR, Beierlein M, Connors BW (1999) Two networks of electrically coupled inhibitory neurons in neocortex. Nature 402:75-79.

Gray CM (1994) Synchronous oscillations in neuronal systems: mechanisms and functions. J Comput Neurosci 1:11-38.

Gray CM, Maldonado PE, Wilson M, McNaughton B (1995) Tetrodes markedly improve the reliability and yield of multiple single-unit isolation from multi-unit recordings in cat striate cortex. J Neurosci Methods 63:43-54.

Grenier F, Timofeev I, Steriade M (2001) Focal synchronization of ripples $(80-200 \mathrm{~Hz})$ in neocortex and their neuronal correlates. J Neurophysiol 86:1884-1898.

Harris KD, Henze DA, Csicsvari J, Hirase H, Buzsáki G (2000) Accuracy of tetrode spike separation as determined by simultaneous intracellular and extracellular measurements. J Neurophysiol 84:401-414.

Hormuzdi SG, Pais I, LeBeau FE, Towers SK, Rozov A, Buhl EH, Whittington MA, Monyer H (2001) Impaired electrical signaling disrupts gamma frequency oscillations in connexin 36-deficient mice. Neuron 31:487-495.

Jones MS, Barth DS (1999) Spatiotemporal organization of fast $(>200 \mathrm{~Hz})$ electrical oscillations in rat vibrissa/barrel cortex. J Neurophysiol 82:1599-1609.

Jones MS, Barth DS (2002) Effects of bicuculline methiodide on fast $(>200$ $\mathrm{Hz}$ ) electrical oscillations in rat somatosensory cortex. J Neurophysiol $88: 1016-1025$.

Jones MS, MacDonald KD, Choi B, Dudek FE, Barth DS (2000) Intracellular correlates of fast $(>200 \mathrm{~Hz})$ electrical oscillations in rat somatosensory cortex. J Neurophysiol 84:1505-1518.

Kandel A, Buzsáki G (1997) Cellular-synaptic generation of sleep spindles, spike-and-wave discharges, and evoked thalamocortical responses in the neocortex of the rat. J Neurosci 17:6783-6797.

Katsumaru H, Kosaka T, Heizmann CW, Hama K (1988) Gap junctions on GABAergic neurons containing the calcium-binding protein parvalbumin in the rat hippocampus (CA1 region). Exp Brain Res 72:363-370.

Le Van Quyen M, Foucher J, Lachaux J, Rodriguez E, Lutz A, Martinerie J, Varela FJ (2001) Comparison of Hilbert transform and wavelet methods for the analysis of neuronal synchrony. J Neurosci Methods 111:83-98.

Leinekugel X, Khazipov R, Cannon R, Hirase H, Ben Ari Y, Buzsáki G (2002) Correlated bursts of activity in the neonatal hippocampus in vivo. Science 296:2049-2052.

Leung LS, Yim CY (1986) Intracellular records of theta rhythm in hippocampal CA1 cells of the rat. Brain Res 367:323-327.

Long MA, Deans MR, Paul DL, Connors BW (2002) Rhythmicity without synchrony in the electrically uncoupled inferior olive. J Neurosci 22:10898-10905.

Maier N, Guldenagel M, Sohl G, Siegmund H, Willecke K, Draguhn A (2002) Reduction of high-frequency network oscillations (ripples) and pathological network discharges in hippocampal slices from connexin 36-deficient mice. J Physiol (Lond) 541:521-528.

McBain CJ, Fisahn A (2001) Interneurons unbound. Nat Rev Neurosci 2:11-23.
O’Keefe J, Nadel L (1978) The hippocampus as a cognitive map. Oxford: Oxford UP.

Palva JM, Lamsa K, Lauri SE, Rauvala H, Kaila K, Taira T (2000) Fast network oscillations in the newborn rat hippocampus in vitro. J Neurosci 20:1170-1178.

Peinado A, Yuste R, Katz LC (1993) Gap junctional communication and the development of local circuits in neocortex. Cereb Cortex 3:488-498.

Penttonen M, Kamondi A, Acsady L, Buzsáki G (1998) Gamma frequency oscillation in the hippocampus of the rat: intracellular analysis in vivo. Eur J Neurosci 10:718-728.

Recce ML, O'Keefe J (1989) The tetrode: a new technique for multiunit extracellular recording. Soc Neurosci Abstr 24:1250.

Sander T, Kretz R, Williamson MP, Elmslie FV, Rees M, Hildmann T, Bianchi A, Bauer G, Sailer U, Scaramelli A, Schmitz B, Gardiner RM, Janz D, Beck-Mannagetta G (1997) Linkage analysis between idiopathic generalized epilepsies and the $\mathrm{GABA}_{\mathrm{A}}$ receptor alpha5, beta3 and gamma3 subunit gene cluster on chromosome 15. Acta Neurol Scand 96:1-7.

Schmitz D, Schuchmann S, Fisahn A, Draguhn A, Buhl EH, Petrasch-Parwez E, Dermietzel R, Heinemann U, Traub RD (2001) Axo-axonal coupling: a novel mechanism for ultrafast neuronal communication. Neuron 31:831-840.

Soh H, Jung W, Uhm DY, Chung S (2001) Modulation of large conductance calcium-activated potassium channels from rat hippocampal neurons by glutathione. Neurosci Lett 298:115-118.

Söhl G, Degen J, Teubner B, Willecke K (1998) The murine gap junction gene connexin 36 is highly expressed in mouse retina and regulated during brain development. FEBS Lett 428:27-31.

Stebbings LA, Todman MG, Phillips R, Greer CE, Tam J, Phelan P, Jacobs K, Bacon JP, Davies JA (2002) Gap junctions in Drosophila: developmental expression of the entire innexin gene family. Mech Dev 113:197-205.

Tamas G, Buhl EH, Lorincz A, Somogyi P (2000) Proximally targeted GABAergic synapses and gap junctions synchronize cortical interneurons. Nat Neurosci 3:366-371.

Traub RD, Bibbig A (2000) A model of high-frequency ripples in the hippocampus based on synaptic coupling plus axon-axon gap junctions between pyramidal neurons. J Neurosci 20:2086-2093.

Traub RD, Miles R, Buzsáki G (1992) Computer simulation of carbacholdriven rhythmic population oscillations in the CA3 region of the in vitro rat hippocampus. J Physiol (Lond) 451:653-672.

Traub RD, Schmitz D, Jefferys JG, Draguhn A (1999) High-frequency population oscillations are predicted to occur in hippocampal pyramidal neuronal networks interconnected by axoaxonal gap junctions. Neuroscience 92:407-426.

Traub RD, Bibbig A, Fisahn A, LeBeau FE, Whittington MA, Buhl EH (2000) A model of gamma-frequency network oscillations induced in the rat CA3 region by carbachol in vitro. Eur J Neurosci 12:4093-4106.

Traub RD, Whittington MA, Buhl EH, LeBeau FE, Bibbig A, Boyd S, Cross H, Baldeweg T (2001) A possible role for gap junctions in generation of very fast EEG oscillations preceding the onset of, and perhaps initiating, seizures. Epilepsia 42:153-170.

Traub RD, Draguhn A, Whittington MA, Baldeweg T, Bibbig A, Buhl EH, Schmitz D (2002) Axonal gap junctions between principal neurons: a novel source of network oscillations, and perhaps epileptogenesis. Rev Neurosci 13:1-30.

Vanderwolf CH (1969) Hippocampal electrical activity and voluntary movement in the rat. Electroencephalogr Clin Neurophysiol 26:407-418.

Venance L, Rozov A, Blatow M, Burnashev N, Feldmeyer D, Monyer H (2000) Connexin expression in electrically coupled postnatal rat brain neurons. Proc Natl Acad Sci USA 97:10260-10265.

Wang XJ, Buzsáki G (1996) Gamma oscillation by synaptic inhibition in a hippocampal interneuronal network model. J Neurosci 16:6402-6413.

Whittington MA, Traub RD, Jefferys JG (1995) Synchronized oscillations in interneuron networks driven by metabotropic glutamate receptor activation. Nature 373:612-615.

Ylinen A, Bragin A, Nadasdy Z, Jando G, Szabo I, Sik A, Buzsáki G (1995) Sharp wave-associated high-frequency oscillation $(200 \mathrm{~Hz})$ in the intact hippocampus: network and intracellular mechanisms. J Neurosci 15:30-46. 